\title{
DECOVALEX-2015: an international collaboration for advancing the understanding and modeling of coupled thermo-hydro- mechanical-chemical (THMC) processes in geological systems
}

\author{
Jens T. Birkholzer ${ }^{1} \cdot$ Alexander E. Bond ${ }^{2} \cdot$ John A. Hudson ${ }^{3} \cdot$ Lanru Jing $^{4} \cdot$ Chin-Fu Tsang ${ }^{1,5} \cdot$ Hua Shao $^{6} \cdot$ Olaf Kolditz $^{7,8}$
}

Received: 20 June 2018 / Accepted: 28 June 2018 / Published online: 18 July 2018

(c) Springer-Verlag GmbH Germany, part of Springer Nature 2018

\section{Introduction}

An important part of the performance and safety assessment of disposal systems for radioactive waste and spent nuclear fuel in deep geological formations is to evaluate the impact of the coupled effects of mechanical deformation, fluid and gas flow through the repository, and thermal loading from the decaying waste. It was recognized early on in safety and performance assessments conducted for geologic disposal sites that to be able to conduct such an evaluation, there was a need to rigorously enhance the theoretical background and to develop models capable of simulating coupled thermohydro-mechanical (THM) processes. More recently, chemical processes have also been added to enable the study of fully coupled THMC processes in geosystems.

The term "coupled processes" implies that each process potentially affects and is affected by the initiation and progress of all other processes. Thus, the response of a rock mass to radioactive waste storage cannot be predicted with confidence by considering each process individually or in direct succession. In the field of rock mechanics and rock

Jens T. Birkholzer

JTBirkholzer@1bl.gov

1 Lawrence Berkeley National Laboratory, Berkeley, USA

2 Quintessa Ltd, Warrington, UK

3 Imperial College (Emeritus), London, UK

4 KTH Royal Institute of Technology (Emeritus), Stockholm, Sweden

5 Uppsala University, Uppsala, Sweden

6 BGR Federal Institute for Geosciences and Natural Resources, Hanover, Germany

7 UFZ Helmholtz Centre for Environmental Research, Leipzig, Germany

8 TUDD Technische Universität Dresden, Dresden, Germany engineering, many studies have been made on two-way couplings TM and HM, but for the repository performance problem, it is essential to study and be able to predict processes with THM coupling, and even full THMC coupling. Such coupling remains a major challenge to the science and engineering community, in part because relevant effects need to be better understood and described with better constitutive relations, but also since the processes have widely different characteristic temporal and spatial scales. Coupled processes of course are not only relevant to geologic disposal of radioactive waste but also play a critical role in a range of other sub-surface engineering activities, such as carbon dioxide sequestration, enhanced geothermal systems, energy storage, as well as unconventional oil and gas production through hydraulic stimulation.

In 1992, recognizing the need to address the modeling challenges related to coupled THM and (in later stages) THMC processes, DECOVALEX was initiated as an international cooperative project of nuclear waste organizations, including implementers, regulators, and research institutes involved in national programs, plus a large number of associated research and modeling teams, providing a wide range of perspectives and solutions to these complex problems. Analysis and comparative modeling of state-of-the-art field and laboratory experiments has been at the core of the collaborative work, with an increasing focus on characterizing uncertainty and blind prediction of experimental results. Since 1992, the project has gone through several 4-year phases, each phase featuring a small number (typically 3-6) modeling challenges of importance to radioactive waste disposal. Five project phases were successfully concluded between 1992 and 2011, results of which have been published in a series of Special Issues in the International Journal of Rock Mechanics and Mining Sciences [vol. 32(5) in 1995, vol. 38 (1) in 2001, and vol. 42(5-6) in 2005], in the Journal of Environmental Geology [vol. 57(6) in 2009], and in the 
Journal of Rock Mechanics and Geotechnical Engineering [vol. 5(1-2), in 2013].

The sixth phase of the DECOVALEX project, here referred to as DECOVALEX-2015, was initiated in 2012 and concluded at the end of 2015. Modeling teams from ten international partner organizations participated in the comparative evaluation of five modeling tasks involving complex field and/or laboratory experiments in Switzerland, France, Japan, and the Czech Republic. Four of the five tasks are related to the coupled processes occurring in the near-field of geologic repositories, as a result of early system perturbations from excavation and emplacement affecting the engineered barrier and the adjacent host rock. The fifth task is related to complex flow and transport patterns in fractured crystalline rock. Together, these tasks addressed a wide range of relevant issues related to engineered and natural system behavior in a variety of potential host rocks.

The 22 manuscripts in this Topical Collection (of papers published in Environmental Earth Sciences from 2015-2018) provide an in-depth overview of the collaborative research efforts conducted in the DECOVALEX-2015 project and how these have advanced the state of the art of understanding and modeling coupled THMC processes. We have focused this collection on four of the DECOVALEX-2015 tasks, which are briefly summarized below together with references to the respective manuscripts. One of the most important characteristics of DECOVALEX is the emphasis on a cooperative research environment and the desire to gain insight by comparative analysis of multiple alternative approaches. This characteristic is reflected in the synthesis papers developed for each task, which provide an overview of the modeling approaches pursued by individual research teams and discuss which concepts and models have been particularly suited for a given THM or THMC problem. These synthesis papers, generally authored by all participating researchers, are followed by more detailed manuscripts describing the research methods and findings of individual teams.

\section{The SEALEX experiment: HM processes in bentonite-based sealing structures}

This task is related to the technical feasibility of the tunnel seals required in geologic repositories for radioactive waste with respect to their safety functions and their expected performance level. The technical feasibility is strongly dependent on the expected behavior of the bentonite-sand mixtures that are envisioned as sealing materials. The modeling activities performed here are centered around the SEALEX in situ test on seal performance conducted in a research alcove in the Tournemire Underground Research Laboratory (URL) in France. Before focusing on all of the complex aspects of the in situ test, research teams were asked to work through preparatory modeling steps of increasing complexity, starting with laboratory and mock-up tests to study the HM behavior of bentonite-sand mixture followed by an analysis of the hydraulic behavior of the rock mass surrounding the in situ seal.

Two synthesis papers provide summary findings for comparative modeling of the laboratory and mock-up studies (Millard et al. 2016) and the in situ experiments (Millard et al. 2017). Detailed results from individual modeling groups can be found in Thatcher et al. (2016a, b), Fraser Harris et al. (2016), Mokni (2016), Xu et al. (2016), and Yi et al. (2017). Thatcher et al. (2016a) investigated Excavation Damage Zone (EDZ) sealing during a water injection test at the Tournemire URL. In a second paper (Thatcher et al. 2016b), the same group developed a new hydro-mechanical model for bentonite resaturation and applied it to the SEALEX experiments. Fraser Harris et al. (2016) developed a nonlinear elastic approach for modelling HM behavior of the SEALEX experiments on compacted MX-80 bentonite. Mokni (2016) analyzed the hydro-mechanical behavior of a compacted bentonite-sand mixture using a double-structure formulation, while $\mathrm{Xu}$ et al. (2016) investigated modeling the one-dimensional consolidation of saturated porous media with degradation-dependent compressibility. Finally, Yi et al. (2017) modeled the SEALEX mock-up test using a hydro-mechanical approach including elastoplasticity of the unsaturated bentonite-sand mixtures.

\section{THM processes in bentonite backfill and argillaceous host rock}

The objective of this task is to improve the understanding of the THM processes occurring after emplacement of heat-emanating waste packages in tunnels backfilled with bentonite situated in an argillaceous host rock. Simulating the coupled THM behavior in such systems is very challenging; it involves complex moisture transport processes induced by strong thermal gradients, significant changes in stress conditions due to temperature increases and bentonite swelling, and last not least considerable spatial and temporal alterations of mechanical and hydraulic properties of the bentonite and the host rock. The task is divided into three sub-tasks, the first two addressing THM behavior in the argillite host rock and bentonite separately before focusing on a more complex experiment featuring bentonite and host rock interactions.

- Study of THM processes in the argillaceous host rock (Opalinus Clay) This sub-task is based on a borehole heater test (HE-D) conducted in the Mont Terri Rock Laboratory in Switzerland between 2004 and 2005. 
- Study of THM processes in bentonite materials Here the teams are asked to model the THM behavior of a laboratory experiment involving a heated bentonite column.

- Study of the HE-E experiment at Mont Terri Rock Laboratory This experiment features a 10-m-long microtunnel equipped with two independently operated heaters emplaced in a bentonite backfilled tunnel segment. Modeling teams first conducted blind predictions of the THM behavior based on learnings from the two previous modeling tasks, followed by interpretive modelling of the observation data.

This task is summarized in three synthesis papers for each of the three sub-tasks, with Garitte et al. (2017a) focusing on a comparative analysis of THM models simulating the HE-D test, Graupner et al. (2018) evaluating collaborative THM modelling of the heated bentonite pellet column, and Garitte et al. (2017b) summarizing the predictive capability of THM models to simulate a complex heated bentonite-clay system as observed in the HE-E experiment. Individual team contributions are given in Pan et al. (2017), Ofoegbu et al. (2017), and Wang et al. (2016), respectively. The first two papers describe the development and testing of new modeling approaches to prepare for this task: Pan et al. (2017) studied the coupled thermo-hydro-mechanical processes in column bentonite tests using a new elastoplastic cellular automaton (EPCA) method, and Ofoegbu et al. (2017) investigated mechanical behavior of unsaturated expansive soils based on the Bishop principle of effective stress. Finally, Wang et al. (2016) analyzed THM behavior in a clay-based engineered and natural barrier system (EBS) and modeled the full complexity of the HE-E experiment.

\section{THMC processes in single fractures}

This task is novel for the DECOVALEX project in that it focuses on fundamental THMC fracture process understanding at the laboratory scale. Such process interactions are potentially of great interest to predicting the performance of the natural barrier in the near-field of radioactive waste disposal facilities. At the same time, they have great relevance to other non-radioactive waste applications such as advancing the resource potential of geothermal energy. The task considers two sets of experiments on artificially induced single fractures in novaculite (micro- or crypto-crystalline quartzite) and granite under mechanical confinement (Bond et al. 2016, 2017). The fractured specimens were subject to throughflow of deionized water under a variety of pressure gradients and temperatures and the resultant water effluent was analyzed for chemical constituents. In addition, detailed surface laser topographic scanning was conducted on some of the fracture surfaces, together with post-experimental
Wood's metal injection, to measure the detail fracture aperture distribution before and after testing, respectively. The experiments showed strong evidence for temporal and coupled variation in fracture aperture opening and produced chemical effluent, clearly indicating strong THMC interaction at a variety of spatial scales. Research teams were asked to construct novel numerical models that could replicate the experimental data (e.g. staring with the chemically simpler novaculite experiment). These models, which are built on a mutually self-consistent conceptual basis, also give insight into the relative importance of the very wide range of candidate process models.

Synthesis analyses of the joint novaculite and granite work conducted by the international modeling teams are given in Bond et al. (2016, 2017). Individual research team results are provided in McDermott et al. (2015), Chittenden et al. (2016), Pan et al. (2016), and Lu et al. (2017). McDermott et al. (2015) developed hybrid numerical and analytical solutions for the simulation of coupled thermal, hydraulic, mechanical and chemical processes during fluid flow through a fractured rock. Chittenden et al. (2016) evaluated the relative importance of THMC processes when analyzing fluid flow experiments in fractured novaculite and fractured granite. Pan et al. (2016) used a specific numerical method referred to as elastoplastic cellular automaton (EPCA) to simulate coupled THMC processes in a single fracture. Finally, Lu et al. (2017) focused on the specifics of water-granite interaction with pressure solution during flow through a single fracture under confining pressure.

\section{The Bedrichov Tunnel: hydrochemical interactions in fractured crystalline rock}

The Bedrichov Tunnel is located in the north of the Czech Republic, in the Jizera Mountains, which are part of the Bohemian Massif. The tunnel, excavated during 1980-1981, connects a water reservoir with a water processing plant, and is $2600 \mathrm{~m}$ long at a maximum $150 \mathrm{~m}$ depth, with the first $890 \mathrm{~m}$ excavated with a tunnel boring machine and the remaining part by drilling-and-blasting. Over the last decades, the facility has been used to understand the hydro-geochemical conditions in the massif and the flow and transport evolution in the granitic rocks surrounding the tunnel. The work presented here builds on a previous study conducted in a previous phase (DECOVALEX-2011) and utilizes a wide range of supporting data from ongoing site work, such as inflows along the tunnel and the geochemical characteristics of those inflows. A stepwise approach was adopted, looking initially at just the hydraulic characteristics of the site, then incorporating non-reactive transport of key tracers and finally reactive transport. Teams were encouraged to use different numerical approaches, which resulted in the use of 
discrete fracture network modeling, continuum modeling, and some hybrid techniques.

A synthesis of the work is discussed in Hokr et al. (2016), comparing the results of three modelling teams simulating the flow and tracer transport in fractured rock surrounding the Bedrichov Tunnel. Some additional investigations are described by Gardner et al. (2016), who investigated the age distribution of fracture discharge using multiple environmental tracers.

\section{Final remark}

As coordinators and guest editors of this Topical Collection, we like to express our thanks to the funding organizations of the DECOVALEX-2015 project, to the research teams and authors of the papers for their scientific contributions, and to the editors of this journal. We hope that the brief summary presented above, and the in-depth research findings in the selected papers, provide an idea of the breadth and depth of cutting-edge research work carried out within the DECOVALEX-2015 project. With this Topical Collection, we also intend to convey to interested readers the value of the DECOVALEX philosophy of cooperation between international researchers of different disciplines using a range of different approaches. Such collaboration means frequent interactions, sharing of data and results, collectively generating new ideas and concepts, raising technical issues in joint communications, and performing critical reviews of each other's work. The insight obtained in such integrated cooperative efforts would have been impossible if the teams had worked independently.

Acknowledgements DECOVALEX is an international research project comprising participants from industry, government and academia, focusing on development of understanding, models and codes in complex coupled problems in sub-surface geological and engineering applications. The authors appreciate and thank the DECOVALEX-2015 funding organizations BGR/UFZ, CAS, US DOE, ENSI, IRSN, JAEA, KAERI, NRC, RWM, and SÚRAO for their financial and technical support of the work described in this Editorial. The statements made in the editorial are, however, solely those of the authors and do not necessarily reflect those of the funding organizations.

\section{References}

\section{The SEALEX experiment: HM processes in bentonite-based sealing structures}

Harris AF, McDermott CI, Bond A, Thatchern K, Norris S (2016) A non-linear elastic approach to modelling the hydro-mechanical behaviour of the SEALEX experiments on compacted MX-80 bentonite. Environ Earth Sci 75:1445. https://doi.org/10.1007/ s12665-016-6240-y
Millard A, Mokni N, Barnichon JD, Thatcher K, Bond A, Fraser-Harris A, McDermott CI, Blaheta R, Michalec Z, Hasal M, Nguyen T-S, Nasir O, Fedors R, Yi H, Kolditz O (2016) Comparative modelling of laboratory experiments for the hydro-mechanical behaviour of a compacted bentonite-sand mixture. Environ Earth Sci 75:1311. https://doi.org/10.1007/s12665-016-6118-z (Synthesis paper)

Millard A, Mokni N, Barnichon JD, Thatcher K, Bond A, Fraser-Harris A, McDermott CI, Blaheta R, Michalec Z, Hasal M, Nguyen T-S, Nasir O, Yi H, Kolditz O (2017) Comparative modelling approaches of hydro-mechanical processes in sealing experiments at the Tournemire URL. Environ Earth Sci 76:78. https://doi. org/10.1007/s12665-016-6324-8. (Synthesis paper)

Mokni N (2016) Analysis of hydro-mechanical behaviour of compacted bentonite/sand mixture using a double structure formulation. Environ Earth Sci 75:1087. https://doi.org/10.1007/s1266 5-016-5872-2

Thatcher KE, Bond A, Norris S (2016a) Engineered damage zone sealing during a water injection test at the Tournemire URL. Environ Earth Sci 75:933. https://doi.org/10.1007/s12665-016-5739-6

Thatcher KE, Bond A, Robinson P, McDermott CI, Harris AF, Norris S (2016b) A new hydro-mechanical model for bentonite resaturation applied to the SEALEX experiments. Environ Earth Sci 75:974. https://doi.org/10.1007/s12665-016-5741-z

Xu X-B, Chen Y-M, Xu W-J, Guo Q-G, Zhan T-L (2016) One-dimensional consolidation of saturated degradable porous media with degradation-dependent compressibility. Environ Earth Sci 75:821. https://doi.org/10.1007/s12665-016-5602-9

Yi H, Wang W, Kolditz O, Shao H, Zhou H (2017) Hydromechanical modelling of the SEALEX Experiments. Environ Earth Sci 73:737. https://doi.org/10.1007/s12665-017-7080-0

\section{THM processes in bentonite backfill and argillaceous host rock}

Garitte B, Nguyen S, Banichon JD, Graupner B, Lee C, Maekawa K, Ofoegbu G, Manepally C, Dasgupta B, Fedors R, Pan P, Feng X-T, Rutqvist J, Chen F, Birkholzer JT, Wang W, Kolditz O, Shao H (2017a) Modelling the Mont-Terri HE-D experiment for the thermal-hydraulic-mechanical response of a bedded argillaceous formation to heating. Environ Earth Sci 76:345. https://doi. org/10.1007/s12665-017-6662-1 (Synthesis paper)

Garitte B, Shao H, Wang X, Nguyen S, Li Z, Rutqvist J, Birkholzer JT, Wang W, Kolditz O, Pan PZ, Feng XT, Lee C, Graupner B, Maekawa K, Manepally C, Dasgupta B, Stothoff S, Ofoegbu G, Fedors R, Barnichon JD (2017b) Evaluation of the predictive capability of coupled thermo-hydromechanical models for a heated bentonite/clay system (HE-E) in the Mont Terri Rock Laboratory. Environ Earth Sci 76:64. https://doi.org/10.1007/ s12665-016-6367-x (Synthesis paper)

Graupner BJ, Shao H, Wang XR, Nguyen TS, Li Z, Rutqvist J, Chen F, Birkholzer JT, Wang W, Kolditz O, Pan PZ, Feng X-T, Lee C, Maekawa K, Stothoff S, Manepally C, Dasgupta B, Ofoegbu G, Fedors R, Barnichon J-D, Ballarini E, Bauer S, Garitte B (2018) Comparative modelling of the coupled thermal-hydrologicalmechanical (THM) processes in a heated bentonite pellet column with hydration. Environ Earth Sci 77:84. https://doi.org/10.1007/ s12665-018-7255-3 (Synthesis paper)

Ofoegbu GI, Dasgupta B, Manepally C, Stothoff S, Fedors R (2017) Modeling the mechanical behavior of unsaturated expansive soils based on bishop principle of effective stress. Environ Earth Sci 76:555. https://doi.org/10.1007/s12665-017-6884-2

Pan P-Z, Yan F, Feng X-T, Wu Z-H (2017) Study on coupled thermohydro- mechanical processes in column bentonite test. Environ Earth Sci 76:618. https://doi.org/10.1007/s12665-017-6942-9 
Wang X, Shao H, Hesser J, Kolditz O (2016) Analysis of the THM behaviour in a clay-based engineered barrier system (EBS): modelling of the HE-E experiment (Mont Terri URL). Environ Earth Sci 75:1350. https://doi.org/10.1007/s12665-016-6116-1

\section{THMC processes in single fractures}

Bond A, Bruský I, Chittenden N, Feng X-T, Shao H, Lang P, Lu R, McDermott C, Neretnieks I, Pan P-Z, Šembera J, Shao H, Yasuhara H, Zheng H (2016) Development of approaches for modelling coupled thermal-hydraulic-mechanical-chemical processes in single granite fracture experiments. Environ Earth Sci 75:1313. https://doi.org/10.1007/s12665-016-6117-0 (Synthesis paper)

Bond A, Bruský I, Cao T, Chittenden N, Fedors R, Feng X-T, Gwo J-P, Kolditz O, Lang P, McDermott C, Neretnieks I, Pan P-Z, Šembera J, Shao H, Watanabe N, Yasuhara H, Zheng H (2017) A synthesis of approaches for modelling coupled thermal-hydraulic-mechanical-chemical processes in a single novaculite fracture experiment. Environ Earth Sci 76:12. https://doi.org/10.1007/s12665-0166326-6 (Synthesis paper)

Chittenden N, McDermott CI, Bond AE, Wilson J, Norris S (2016) Evaluating the importance of different coupled thermal, hydraulic, mechanical and chemical process simulations during fluid flow experiments in fractured novaculite and fractured granite. Environ Earth Sci 75:1133. https://doi.org/10.1007/s12665-016-5938-1

Lu R, Watanabe N, He W, Jang E, Shao H, Kolditz O, Shao H (2017) Calibration of water-granite interaction with pressure solution in a flow-through fracture under confining pressure. Environ Earth Sci 76:417. https://doi.org/10.1007/s12665-017-6727-1

McDermott CI, Bond A, Harris AF, Chittenden N, Thatcher K (2015) Application of hybrid numerical and analytical solutions for the simulation of coupled thermal, hydraulic, mechanical and chemical processes during fluid flow through a fractured rock. Environ Earth Sci 74:7837. https://doi.org/10.1007/s12665-015-4769-9

Pan P-Z, Feng X-T, Zheng H, Bond A (2016) An approach for simulating the THMC process in single novaculite fracture using EPCA. Environ Earth Sci 75:1150. https://doi.org/10.1007/s1266 5-016-5967-9

\section{The Bedrichov Tunnel: hydrochemical interactions in fractured crystalline rocks}

Gardner WP, Hokr M, Shao H, Balvin A, Kunz H, Wang Y (2016) Investigating the age distribution of fracture discharge using multiple environmental tracers, Bedrichov Tunnel, Czech Republic. Environ Earth Sci 75:1374. https://doi.org/10.1007/s12665-0166160-x (Synthesis paper)

Hokr M, Shao H, Gardner WP, Balvín A, Kunz H, Wang Y, Vencl M (2016) Real-case benchmark for flow and tracer transport in the fractured rock. Environ Earth Sci 75:1273. https://doi. org/10.1007/s12665-016-6061-z (Synthesis paper) 